\title{
Reflexões sobre o princípio da Função Social da Propriedade e a aplicação do parcelamento, edificação ou utilização compulsórios de imóveis urbanos
}

\author{
Lenimar Gonçalves Rios, \\ José Marques Carriço*
}

\begin{abstract}
Resumo Este trabalho apresenta reflexões acerca dos limites da aplicação do parcelamento, edificação ou utilização compulsórios, para garantia do cumprimento da função social da propriedade urbana no Brasil e em especial na Região Metropolitana da Baixada Santista. Discute-se a gênese desse instrumento de política urbana e sua relevância para o enfrentamento da retenção especulativa de imóveis, para apresentar um balanço de sua aplicação em municípios brasileiros, com destaque para a mencionada região, onde praticamente não foi implementado, à despeito de seu padrão socioespacial insustentável de ocupação urbana.
\end{abstract}

Palavras-chave: função social da propriedade urbana, parcelamento, edificação ou utilização compulsórios, Região Metropolitana da Baixada Santista.

Reflexiones sobre el principio de la Función Social de la Propiedad y la aplicación de la parcelación, construcción o el uso obligatorio de inmuebles urbanos

Resumen Este artículo presenta reflexiones sobre los límites de la parcelación, construcción o el uso obligatorio de inmuebles urbanos, para garantizar el cumplimiento de la función social de la propiedad urbana en Brasil y especialmente en la Región Metropolitana de Baixada Santista. Este documento analiza la génesis de este instrumento de política urbana y su relevancia para enfrentar la retención especulativa de inmuebles, a fin de presentar una evaluación de su aplicación en los municipios brasileños, especialmente en esa región donde prácticamente no se implementó, a pesar de su patrón socioespacial insostenible de ocupación urbana.

Palabras clave: Función social de la propiedad urbana, Parcelación, construcción o el uso obligatorio, Región Metropolitana de Baixada Santista.
Reflections on the principle of the Social Function of Property and the application of compulsory urban land subdivision, building or use

Abstract This paper presents reflections on the limits of compulsory urban land subdivision, building or use, to guarantee the fulfillment of the social function of urban property in Brazil and especially in the Baixada Santista Metropolitan Region. The genesis of this urban policy instrument and its relevance are discussed to face the speculative retention of real estate, in order to present a balance of its application in Brazilian municipalities, especially in this region where it was practically not implemented, despite its unsustainable socio-spatial pattern of urban occupation.

Keywords: social function of urban property, compulsory urban land subdivision, building or use, Baixada Santista Metropolitan Region. 
O

tema deste trabalho é o principio da função social da propriedade (FSP) urbana e o principal instrumento urbanístico que os municipios dispõem para efetivá-lo, o Parcelamento, Edificação e Utilização Compulsórios (PEUC) da propriedade urbana. Previsto na Constituição Federal de 1988 e regulamentado pela Lei $n^{\circ} 10.257$, de 10 de julho de 2001, Estatuto da Cidade, o dispositivo aplica-se a imóveis vazios, não utilizados ou subutilizados, localizados em áreas urbanas dotadas de infraestrutura, equipamentos e serviços urbanos.

O PEUC, juntamente com o Imposto Predial e Territorial Urbano (IPTU) Progressivo no Tempo e a Desapropriação de Imóveis com Pagamento em Títulos da Dívida Pública, é instrumento jurídico e político para que municípios planejem seu crescimento em bases inclusivas, pois oferece condições para intervir em imóveis que, por estarem ociosos quanto ao uso e à ocupação, especulando à espera de valorização, causam grandes prejuízos econômicos e sociais ao desenvolvimento urbano.

Além dos fundamentos legais do PEUC, serão avaliadas as dificuldades de aplicação do instrumento nos municípios, questão que será ilustrada com dados de pesquisa realizada em 2014, pelo Ministério da Justiça com a colaboração da Universidade Federal do $A B C$, que ofereceu um panorama sobre a aplicação dos referidos instrumentos em municípios brasileiros. Também será apresentado e analisado levantamento da situação da aplicação do dispositivo legal nos municípios da Região Metropolitana da Baixada Santista (RMBS), assim como da aplicação no município de Santos, polo regional, cuja área central apresentou nas últimas décadas grande crescimento de imóveis desocupados.

A pertinência da avaliação da incidência do PEUC nesta região, integrante do complexo regional denominado Macrometrópole Paulista ${ }^{1}$, decorre de suas características econômicas e socioambientais, pela importância do Porto de Santos e do parque industrial de Cubatão, em um contexto de ocupação horizontal periférica, possibilitada pela infraestrutura viária que induziu o desenvolvimento disperso e fragmentado de

* Lenimar Gonçalves Rios é Arquiteta e Urbanista, Professora do Curso de Arquitetura e Urbanismo da Universidade Católica de Santos, ORCID <https://orcid. org/0000-0001-5069-7174>. José Marques Carriço é Arquiteto e Urbanista, Professor do Programa de Pós-graduação Stricto Sensu em Direito Ambiental e Internacional e pelo Curso de Arquitetura e Urbanismo da Universidade Católica de Santos, ORCID <https://orcid.org/00000002-2249-5409>. empreendimentos imobiliários voltados à produção de domicílios de uso ocasional, vinculados à atividade turística balneária. Assim, estudar a eficácia de políticas de enfrentamento à retenção especulativa de imóveis urbanos, pode fornecer importantes subsídios para a reorientação das políticas urbanas.

\section{Especulação imobiliária e a construção da cidade horizontal e desigual}

O processo de urbanização capitalista ocorre acompanhado de intensa valorização do solo, fator essencial para reprodução do capital, resultando na distribuição socialmente desigual da ocupação do tecido urbano. 
10 conceito de Macrometrópole remonta a estudos elaborados pela Empresa Paulista de Planejamento Metropolitano, nos anos 1990, e atualmente se refere ao conjunto de unidades regionais institucionalizadas, no estado de São Paulo, formado pelas Regiões Metropolitanas de São Paulo, Campinas e do Vale do Paraíba e Litoral Norte, dos Aglomerados Urbanos de Jundiaí e de Piracicaba, além da RMBS.
Nas sociedades caracterizadas por grande concentração da riqueza, como no Brasil, o processo de urbanização fundado na valorização imobiliária produz ocupação extensiva e desigual, pois as camadas de menor renda tendem a ocupar espaços na periferia das áreas urbanizadas, onde imóveis são mais baratos porque os benefícios urbanos não existem ou são incompletos. Esses segmentos apropriam-se de forma inadequada e irregular dos espaços que não interessam ao mercado imobiliário, por serem de proteção permanente ou de risco e até avançam sobre áreas rurais. Isso ocorre a despeito da capacidade de adensamento nos espaços onde a urbanização é completa e da existência em seu interior de terrenos não utilizados ou subutilizados, assim como imóveis edificados vazios.

Em situação não muito distinta encontram-se aqueles que conseguem instalar-se nos espaços urbanizados, mas que para isso se sujeitam a morar em condições sanitárias ou de segurança inadequadas, em cortiços ou ocupações irregulares de edifícios não utilizados, as chamadas ocupações, geralmente em áreas centrais.

Comum em boa parte das cidades brasileiras, essa situação envolve principalmente imóveis à espera de maior valorização, os quais, à medida que reduzem a oferta de terra urbanizada para habitação, atividades econômicas e serviços públicos elevam o preço do solo e, enquanto tal, servem somente à especulação imobiliária. Em geral. essa valorização se dá graças a investimentos públicos e de terceiros na vizinhança e não por esforço do proprietário do imóvel ocioso e retido à espera de "melhor oportunidade" para colocação no mercado.

Campos Filho (apud CASTILHO, 1993, p.47) define a especulação imobiliária "como ganho de um empreendedor que não é obtido por investimento próprio". Para Saleme (2018, p: 31))

A especulação é a retenção do imóvel que se mantém ocioso, sem a devida ocupação, aguardando o aquecimento do mercado imobiliário ou ainda sua gentrificação de forma a viabilizar essa valorização.

A percepção corrente é que o problema da ocupação de nossas cidades se situa apenas na insuficiência quanto a distribuição da infraestrutura, equipamentos e serviços urbanos no espaço ocupado. Supõe-se que com investimentos sejam supridas as carências quando, na verdade, elas são resultado do próprio processo de crescimento fundado na valorização imobiliária, que funciona como espiral, empurrando continuamente o crescimento da cidade para além dos limites urbanizados. Essa dinâmica

[...] tem muitas vezes um fenômeno por trás de si, que impacta de forma significativa no processo de desenvolvimento da cidade: os vazios urbanos. (SANCHES et al, 2018, p. 272)

De acordo com Beltrame (apud SANCHES et al, 2018, p.273) os vazios urbanos se materializam de várias formas

[...] abrangem desde a inexistência de construção, à não ocupação, à decadência, ao não uso e ao subaproveitamento dos espaços, sejam eles terrenos ou edificações consideradas como urbanas [...] 
Para Rodrigues (2018, n.p.) a reserva especulativa se materializa não somente pelos imóveis não utilizados e subutilizados, mas também em "[...] exiguidade de terra urbanizada, ausência de infraestrutura, imóveis abandonados, vacantes e em ruínas".

Em suma, a especulação imobiliária acarreta expressivos prejuízos ambientais, sociais e econômicos ao desenvolvimento urbano dos municípios, que se debatem com ociosidade da ocupação de áreas bem servidas de infraestrutura e serviços e, contraditoriamente, com necessidade permanente de investimentos para estender redes de água, esgoto, drenagem e energia elétrica, pavimentação, além de equipamentos comunitários. Devese computar também investimentos requeridos para saldar os passivos ambientais e sociais criados com a ocupação de áreas de proteção permanente e de risco.

20 termo faculta enseja questionar se é opção ou dever do município exigir o PEUC. Para Frota (2014), como o PEUC é obrigatório como conteúdo dos planos diretores municipais segundo o Estatuto da Cidade, a "faculdade" prevista na CF de 1988 tem a forma de um poderdever da administração pública.

3 A redação do $\S 4^{\circ}$ do artigo 182 da CF e do artigo $5^{\circ}$ do Estatuto da Cidade, que trata do PEUC, utiliza o termo "solo urbano" para referir-se ao objeto de aplicação do instrumento. Isso enseja interpretação jurídica de que o dispositivo não se aplicaria a imóveis edificados, de sorte que um edifício vazio não estaria descumprindo o princípio da FSP. Contudo, em interpretação diversa, muitos municípios têm considerado imóveis edificados vazios como passíveis de utilização compulsória e estabelecido critérios para aplicação do PEUC.

\footnotetext{
4 Por força da Resolução $n^{\text {a }} 43$, do Senado Federal, de 21 de dezembro de 2001, que regulamentou dispositivo da Lei de Responsabilidade Fiscal (LRF), é vedado a estados e municípios ofertar títulos da dívida pública até $\mathrm{o}$ ano de 2020, exceto para refinanciamento de títulos existentes no mercado, o que reduz os instrumentos disponíveis para fazer frente ao problema.
}

\section{A função social da propriedade e o combate à especulação imobiliária}

O PEUC, Parcelamento, Edificação ou Utilização Compulsórios de solo urbano não edificado, subutilizado e não utilizado é a resposta dada pela CF de 1988 para que os municípios combatam a retenção especulativa de imóveis e seus efeitos sobre o desenvolvimento urbano. No artigo 182, § $4^{\circ}$, a CF faculta ${ }^{2}$ ao poder público municipal exigir do proprietário de solo urbano não edificado, subutilizado ou não utilizado 3

\section{[...] que promova seu adequado aproveitamento, sob pena, sucessivamente, de: \\ I - parcelamento ou edificação compulsórios; [...]}

Além de exigir que o proprietário dê destinação adequada ao imóvel ocioso, o artigo 182 , § $4^{\circ}$, da CF prevê como sanções pelo não cumprimento:

\section{$[\ldots]$}

II - imposto sobre a propriedade predial e territorial urbana progressivo no tempo;

III - desapropriação com pagamento mediante títulos da dívida pública de emissão previamente aprovada pelo Senado Federal, com prazo de resgate de até dez anos, em parcelas anuais, iguais e sucessivas, assegurados o valor real da indenização e os juros legais. ${ }^{4}$

A obrigatoriedade de dar destinação a imóveis ociosos está fundamentada em um dos princípios constitucionais de 1988, a FSP, concepção de direito que submete a propriedade privada ao interesse social e coletivo. Com isso não é mais possível conceber a propriedade como direito absoluto, mas como algo que deverá estar subordinado à função social.

Segundo Josserand (apud Machado, 2014)

[...] a evolução social e econômica [...] colocou à prova o absolutismo do direito de propriedade, abrindo-Ihe novas fronteiras, passando a propriedade a ser concebida, ordenada e exercida em face do bem estar da coletividade. (MACHADO, 2014, p. 38) 
Comentando os limites impostos ao proprietário, Machado argumenta:

[...] As limitações aos poderes do proprietário surgem em função dos interesses da sociedade, que afirma o caráter eminentemente social da propriedade, considerando sua origem e sua finalidade. (MACHADO, 2014, p. 39)

Num contexto em que tradicionalmente a propriedade privada foi tomada como direito absoluto, a FSP como pilar do direito constitui novo paradigma. Nestes termos, para Sanches et al (2018, p: 274)

A função social da propriedade não se constitui um limitador ao exercício da propriedade, ela constitui o próprio conceito de propriedade, é elemento da estrutura do conceito de propriedade privada.

Referindo-se aos novos paradigmas constitucionais, os autores concluem:

A propriedade privada protegida constitucionalmente é aquela que cumpre sua função social. (SANCHES et al, 2018, p. 274)

Tendo por alicerce o princípio da FSP pode-se afirmar que o PEUC constitui dispositivo

5 Os autores referem-se à FSP em análise da aplicação do IPTU Progressivo, que entende-se aplicável ao PEUC, instrumento ao qual o citado tributo está vinculado.

6 Pela CF o plano diretor é obrigatório para municípios com mais de 20.000 habitantes. O Estatuto da Cidade definiu outras cinco situações em que o plano é obrigatório, entre as quais para municípios que, mesmo com população inferior ao estipulado na Constituição, pretendam aplicar O PEUC.
[...] que passa a combater a utilização do espaço urbano apenas como instrumento de valorização do capital individual, sem levar em consideração as necessidades e os interesses da coletividade. (SANCHES et al, 2018, p. 262)

A CF de 1988 apresenta-se, consequentemente, como divisor de águas no trato do direito de propriedade. Nesse sentido, a especulação imobiliária, estratégia para valorizar a propriedade no modo de produção capitalista e da qual os vazios urbanos constituem elemento importante, não mais encontra respaldo no ordenamento jurídico brasileiro.

Com isso governos locais adquirem condições para planejar o desenvolvimento, promovendo adequado aproveitamento de áreas dotadas de infraestrutura, equipamentos e serviços e reduzindo os custos sociais e financeiros da urbanização pelo maior controle da expansão da ocupação.

Cabe salientar que o artigo 182 da CF foi regulamentado pelo Estatuto da Cidade, porem sua aplicação não é direta, cabendo ao plano diretor apontar quais áreas do município são passíveis de aplicação de PEUC ${ }^{6}$.

Além disso, ao definir o conteúdo mínimo obrigatório do plano diretor, o Estatuto da Cidade estabelece no artigo 42, inciso I, que a delimitação dessas áreas deverá observar a existência de infraestrutura e de demanda para utilização, numa inequívoca sinalização de uso do instrumento para combate à retenção especulativa.

Referindo-se ao artigo 182 e seus parágrafos, Cymbalista e Freire (2009, p. 6) chamam a atenção para o fato de que a CF de 1988 atribuiu papel especial aos municípios, ao Ihes conferir "a capacidade de estabelecer alguns dos conteúdos para definição dos direitos de propriedade". Ou seja, é ao município que cabe a responsabilidade de fazer cumprir o princípio constitucional da FSP, elemento estratégico para planejar seu desenvolvimento em bases sustentáveis. 


\section{O PEUC como instrumento de efetivação da função social da propriedade}

Historicamente o conceito de propriedade passou por várias transformações. Atribuise ao Código Civil francês de 1804, o "código napoleônico", a definição que se tornou clássica, influenciando códigos civis do mundo inteiro, inclusive o brasileiro. Este código estabeleceu a nova ordem jurídica ensejada pela Revolução Francesa, de 1789, e segundo Bernardes (2003), fixou a propriedade com características de direito quase absoluto.

Entretanto, ainda no século XIX, como fruto da Revolução Industrial, conflitos envolvendo capital e trabalho, ligados entre outros fatores à dificuldade de acesso de grande parte da classe trabalhadora a bens básicos para sua reprodução, como habitação, originaram questionamentos que atingiam diretamente o conceito do direito de propriedade vigente.

Nesse período tomaram corpo as teorias sobre o modo de produção capitalista, em particular o debate sobre as contradições envolvendo a produção social da riqueza e sua apropriação privada. Bernardes (2003) aponta como digna de registro a influência das teorias marxistas que apontam para a coletivização da propriedade individual.

7 Entre as encíclicas editadas entre final do século XIX e meados do século XX, que abordam conflitos entre capital e trabalho, destacam-se: Rerum Novarum (Das Coisas Novas), de 1891 orienta "sobre as condições dos operários"; Quadragesimo Anno, de 1931, que celebra quarenta anos de edição da Rerum Novarum e orienta "sobre o aperfeiçoamento da ordem social"; Mater et Magistra (Mãe e Mestra), de 1962, que orienta "sobre a recente evolução da questão social à luz da doutrina cristã".
Refletindo esse ambiente de contradições, as encíclicas papais ${ }^{7}$ passaram a interferir nesses embates, com crítica aos postulados marxistas e apelando a uma posição conciliatória, trazendo para o centro da sua doutrina social os conflitos entre trabalhadores e patrões. Segundo Maria Silvia Zanella Di Pietro (apud BERNARDES, 2003) as encíclicas associaram

\section{[...] a propriedade a uma função social, ou seja, à função de servir como instrumento} para acesso de bens e serviços à subsistência de toda humanidade.

Nesse ambiente de conflitos dissemina-se o conceito de FSP, termo originalmente formulado por Leon Duguit, em 1911. O direito de propriedade como algo absoluto [...] cede espaço à ideia de que a propriedade era, em si, uma função social". (BERNARDES, 2003)

No Brasil, o termo aparece pela primeira vez na CF de 1934, que mantinha a propriedade como direito inviolável, trazida desde a Constituição de 1824, primeira após a Independência. Porém, em 1934 ressalvava-se que tal direito "não poderia ser exercido contra o interesse social ou coletivo na forma que a lei determinar" (SANTOS, 2018 , p. 26). Segundo este autor (2018, p. 25), a CF de 1937, influenciada pelo positivismo, "que culminou no fascismo europeu" manteve o princípio da inviolabilidade da propriedade mas suprimiu a vinculação desse direito ao interesse social ou coletivo.

A CF de 1967, no art. 157, define a FSP, pela primeira vez, como princípio para realização da justiça social. Entretanto, como observa Santos (2018, p. 29) "ainda sem reconhecê-la de fato como tal".

Somente na CF de 1988 que a propriedade "adquire status de direito que tem uma função social" (SANTOS, 2018, p. 29). Além disso, o que diferenciou esta CF da anterior, foi a criação de condições para definir de forma objetiva esse princípio, delegando aos 
municípios competência para fixar, em seus planos diretores, as exigências fundamentais para que a propriedade urbana cumpra função social de modo a garantir o bem estar de seus habitantes (artigo 182, § $2^{\circ}$ ).

Com objetivo de assegurar esse princípio, a CF oferece base jurídica para que os municípios exijam de proprietários de imóveis ociosos o parcelamento ou edificação PEUC (artigo 182, § $4^{\circ}$, inciso I) e, caso não haja atendimento, penalizem com aplicação de IPTU Progressivo no Tempo (art. 182, $\S 4^{\circ}$, inciso II) e ao final com desapropriação a ser paga com títulos da dívida pública municipal (art. 182, § $4^{\mathrm{a}}$, inciso III).

O Estatuto da Cidade deu aplicabilidade aos princípios estabelecidos no artigo 182 da CF, ao definir diretrizes e formas de utilização de variadas ferramentas de intervenção, dentre os quais o PEUC e instrumentos associados que proporcionam eficácia à sua aplicação, como IPTU Progressivo no Tempo, Consórcio Imobiliário e Desapropriação com pagamento em Títulos da Dívida Pública.

Importante frisar que a inserção do princípio da FSP no texto constitucional associada a mecanismos que lhe dão efetividade, como o PEUC e os demais instrumentos de sanção, foi resultado de lutas de movimentos populares, os quais, na década de 1960 amadureceram a ideia de um projeto de reforma urbana.

Convencidos que não bastava reivindicar melhorias para seus bairros e regiões, almejavam ir além, alterando os fatores da dinâmica urbana que produzem desigualdades e propondo, para isso, a utilização de mecanismos novos e eficazes no controle do acesso ao solo urbanizado. Além disso, a proposta da reforma urbana era parte de agenda mais ampla, de reformas de base, que tinham como horizonte promover modificações estruturais na sociedade brasileira, visando reduzir a desigualdade social.

O golpe de 1964 atingiu duramente as organizações populares e as reformas de base, cujo debate só foi retomado no final dos anos 1970, quando em meio à crise econômica e institucional os movimentos sociais recuperaram protagonismo no cenário político nacional.

A criação do Movimento Nacional da Reforma Urbana (MNRU), em 1985, foi um salto de qualidade pois as organizações sociais passaram a trabalhar de maneira mais estruturada e a luta ganhou abrangência nacional.

A elaboração da nova CF, com caráter democrático, após 21 anos sob tutela militar, ensejou a apresentação de proposta de emenda popular, subscrita por entidades regionais e por entidades organizadas nacionalmente como o Instituto dos Arquitetos do Brasil, Federação Nacional dos Engenheiros, Federação Nacional dos Arquitetos, Articulação Nacional do Solo Urbano e Associação Nacional dos Mutuários do BNH.

A discussão da emenda à Constituição gerou acirrados debates e mobilizações contrárias à sua aprovação, como a do grupo Tradição, Família e Propriedade. Conforme Saule Jr. e Uzzo (2009 [on line]).

[...] a função social da propriedade figurava como a maior ameaça aos grupos conservadores, como uma ameaça ao direito de propriedade. 
As propostas de reforma urbana inseridas na CF resumiram-se aos artigos 182 e 183, ficando sua execução condicionada a regulamentação por lei específica (Estatuto da Cidade), que tramitou por mais de 13 anos no Congresso Nacional, demora que revela o nível de tensões suscitadas com a nova condição jurídica atribuída à propriedade.

\section{Quadro da regulamentação e aplicação do PEUC nos mu- nicípios brasileiros}

8 Exemplo desse embate é a Proposta de Emenda à Constituiçao $n^{\circ} 80 / 2019$, que tramita no Senado, com objetivo de alterar o artigo 182 da CF, que define a FSP, subvertendo o princípio definido para a citada função. De acordo com Nota Técnica do Instituto Brasileiro de Direito Urbanístico (IBDU, 2019), essa PEC é inconstitucional porque suas motivações são incompatíveis com o princípio constitucional da FSP e outros direitos e garantias individuais. Nesse sentido a proposta incide sobre cláusula pétrea ou seja, sobre dispositivo constitucional que só pode ser alterado através de Congresso Constituinte.

9 Em Brasil (2015) é apresentado estudo minucioso dos mecanismos de implantação, assim como entraves técnicos e institucionais, que deverão ser superados para implementação do PEUC.

10 A maioria dos municípios brasileiros é de pequeno porte. Segundo Planjetar (2017), o IBGE estimou, para 2017, haver 3.803 $(68,3 \%)$ de um total de 5.570 municípios brasileiros com até 20.000 habitantes. Mas nos casos previstos nos incisos II ao $\mathrm{VI}$, do artigo 41, do Estatuto da Cidade, o plano diretor é obrigatório mesmo para municípios com menos de 20.000 habitantes.

\footnotetext{
11 Aplicar o PEUC significa notificar os proprietários de imóveis vazios, não edificados ou não utilizados a procederem ao parcelamento, edificação ou utilização sob pena de sanções com IPTU Progressivo no Tempo e Desapropriação com Pagamento com Títulos da Dívida Pública.
}

Com frequência, por questões de natureza política ou técnica, a aplicação do PEUC, do IPTU Progressivo no Tempo e Desapropriação com Pagamento com Títulos da Dívida Pública, tem se limitando a citações em planos diretores, sem qualquer eficácia no combate à utilização do espaço urbano ocioso como meio de valorização do capital.

De um lado estão aspectos políticos relacionados à natureza da CF de 1988, que, embora construída com grande mobilização da sociedade civil e por isso abraçando conteúdo de Estado Social, com objetivo de reduzir as desigualdades, manteve garantias liberais, como propriedade privada e economia de mercado, fatores que dificultam ações para reduzir os efeitos das externalidades do livre mercado, entre as quais as que submetem o solo urbano a movimentos especulativos ${ }^{8}$.

De outro lado, avolumam-se dificuldades técnicas e institucionais dos municípios para levar adiante a implementação dos mecanismos compulsórios para cumprimento da FSP.

As dificuldades ficaram evidenciadas em pesquisa realizada por Brasil (2015), sob coordenação de Rosana Denaldi. Abrangendo um espaço de treze anos de vigência do Estatuto da Cidade, portanto com tempo suficiente para gerar resultados, apurou-se que, dos 5.565 municípios existentes no Brasil, 2.658 (48\%) possuíam plano diretor e destes somente 521 (20\%) contavam com lei específica de PEUC? .

É importante lembrar que, de acordo com o Estatuto da Cidade, o PEUC é parte do conteúdo obrigatório do plano diretor, que deverá prever área de incidência do instrumento. Embora os planos não sejam obrigatórios para municípios com menos de 20 mil habitantes ${ }^{10}$, tal exigência não considera o fato de que municípios com quantitativo populacional maior, quando apresentam baixo dinamismo econômico, nem sempre comportam a utilização do instrumento, por não apresentarem situações relevantes de solo não parcelado, edificado ou imóveis não utilizados (BRASIL, 2015).

Entre outros, a pesquisa focalizou mais detalhadamente 110 municípios que, pela escala populacional, tendiam a apresentar necessidade de aplicação do PEUC, em virtude de seu dinamismo econômico, assim como de problemas decorrentes da expansão urbana e que por isso contavam com legislação específica de PEUC. Nessa situação foram identificados 27 capitais e 76 municípios com população entre 101.000 e 500.000 habitantes, além de 7 municípios com mais de 500.000 habitantes.

Conforme a Tabela 1, de 27 capitais, somente 8, que correspondem a 30\% do universo pesquisado, tinham legislação específica de PEUC e IPTU Progressivo no Tempo: Campo Grande, Cuiabá, Curitiba, Goiânia, João Pessoa, Palmas, São Paulo e Teresina. Desse conjunto de 8 municípios, apenas 4 (15\%) aplicavam ${ }^{11}$ o PEUC e IPTU Progressivo, Curitiba, Goiânia, Palmas e São Paulo. 


\begin{tabular}{l|c|c}
\hline \multirow{2}{*}{ Categoria } & \multicolumn{2}{c}{$\begin{array}{c}\text { PEUC e IPTU Progressivo no Tempo } \\
\text { (\% do universo pesquisado) }\end{array}$} \\
\cline { 2 - 3 } & com legislação & $\begin{array}{c}\text { com legislação e } \\
\text { aplicação }\end{array}$ \\
\hline Capitais (total 27) & 30 & 15 \\
\hline $\begin{array}{l}\text { Municípios com População de 100 mil } \\
\text { a 500 mil habs (total 76) }\end{array}$ & 16 & 2,6 \\
\hline $\begin{array}{l}\text { Municípios com População acima de } \\
500 \text { mil habs. (Total 7) }\end{array}$ & 71 & 29 \\
\hline
\end{tabular}

Total Geral: 110 municípios

Tabela 1: Síntese da pesquisa PEUC e IPTU Progressivo no Tempo - regulamentação e aplicação. Fonte: BRASIL, 2015.

\footnotetext{
12 Como destacado à nota 3 , embora o Estatuto não faça referência explicita a imóveis edificados, mas sem utilização, pois o art. $5^{\circ}$ refere-se a solo urbano apenas, alguns municípios incluem a categoria "imóveis edificados", caso em que o plano diretor ou lei específica define condições para que um imóvel seja considerado não utilizado. Trabalham com essa interpretação, entre outros, os municípios de Santos, São Paulo, Curitiba e Santo André.
}

Dos 76 municípios que não são capitais, cujas populações compreendiam entre 101.000 e 500.000 habitantes, apenas 12 (16\% do total) tinham legislação específica de PEUC e ou IPTU Progressivo no Tempo, sendo que destes, apenas 2 (2,6\%) aplicavam os instrumentos. Quanto aos 7 municípios com mais de 500.000 habitantes, 5 (71\%) contavam com PEUC e IPTU Progressivo regulamentados, mas somente 2 (29\%) os aplicavam.

Esses dados mostram que, na prática, à medida que o processo de efetivação do PEUC avança da regulamentação para a implementação, há redução drástica do número de municípios que levam adiante o processo, entravado por razões políticas ou de ordem técnica e institucional.

A pesquisa revelou que as dificuldades afetam até municípios cujo porte supõe estruturas de gestão mais aptas para o trato das questões decorrentes da implementação. Além disso, constatou-se que, algumas vezes, o instrumento é utilizado de forma meramente arrecadatória e não como garantidor de uma política urbana sustentável.

A aplicação do PEUC começa com a identificação e delimitação, no plano diretor ou lei específica, das áreas sujeitas a este instrumento ${ }^{12}$, acompanhada de parâmetros que definam essas situações, bem como a fixação de condições e prazos que os proprietários devem observar, a partir do recebimento de notificação.

A efetivação da aplicação do PEUC se dá com esta notificação, mas a sua eficácia depende de sanções ao imóvel que não esteja parcelado, edificado ou que não atenda ao coeficiente de aproveitamento mínimo determinado no plano diretor. Por essa razão, sua aplicação está associada à incidência dos mencionados instrumentos sucessivos de sanção.

Em pesquisa realizada nos municípios do Estado do Rio de Janeiro, Magalhães e Ribeiro (2016) ouviram de gestores municipais que um dos problemas do PEUC é o tempo de espera dos resultados, geralmente avançando além dos 4 anos de mandato dos prefeitos, uma vez que é necessário aplicar o IPTU Progressivo no Tempo pelo prazo de no mínimo cinco anos para então, caso o proprietário continue não atendendo ao 
13 Nada indica, até o momento, que a política de operações de crédito de Estados, Distrito Federal e Municípios, sobre os quais incide a Resolução n 43/2001, venha a ser alterada antes de expirar sua validade, em 2020.
14 O Executivo deve delimitar os imóveis sujeitos ao PEUC de forma planejada, inclusive articulando a Zonas Especiais de Interesse Social (ZEIS), onde o uso habitacional seja desejável. intimado pelo Executivo municipal, este proceda à Desapropriação com Pagamento com Títulos da Dívida Pública.

Neste caso, por ter caráter punitivo, pelo fato de o imóvel não estar atendendo a função social estabelecida pelo plano diretor, segundo artigo $8^{\circ}, \S 2^{\circ}$, do Estatuto, o valor da indenização,

I - Refletirá o valor da base de cálculo do IPTU, descontado o montante incorporado em função de obras realizadas pelo Poder Público na área onde o mesmo se localiza após a notificação".

II - não computará expectativas de ganhos, lucros cessantes e juros compensatórios.

Ocorre que, por força da já mencionada Resolução n 43/2001, do Senado Federal, que regulamentou dispositivo da $\mathrm{LRF}^{13}$, limita-se fortemente o instrumento da desapropriação, que permite finalizar o processo de acordo com o interesse do município, ou seja, imitir-se na posse do imóvel sem deixar de penalizar o proprietário infrator.

Entretanto, mesmo findo o prazo de cinco anos, sem que o proprietário atenda ao intimado, o poder público deverá continuar aplicando o IPTU Progressivo pela alíquota máxima, situação que gera impasse pois, se por um lado mantém a sanção, por outro, não é suficiente para garantir que o proprietário proceda ao que realmente interessa, que é cumprir a FSP determinada pelo Plano Diretor.

Ao proprietário que não deseja ser penalizado resta o Consórcio Imobiliário, que pode ser proposto ao Executivo para viabilizar financeiramente o aproveitamento do imóvel. $\mathrm{O}$ artigo 46, $\S 1^{\circ}$ do Estatuto da Cidade define esse instrumento como

\section{[...] a forma por meio do qual o proprietário transfere ao poder público municipal} seu imóvel e, após a realização de obras recebe, como pagamento, unidades urbanizadas ou edificadas, ficando as demais unidades incorporadas ao patrimônio público.

Para o poder público, o Consórcio poderá ser um meio de viabilizar a aquisição de áreas para urbanizar ou edificar, indenizando o proprietário ao final das obras com unidades imobiliárias, operação análoga a que entre si estabelecem proprietários privados. Nesse sentido poderá ser utilizado de forma estratégica para viabilização de empreendimentos habitacionais de interesse social ${ }^{14}$, sendo que o pagamento do valor do terreno dar-se-á em lotes urbanizados ou área construída e ocorrerá após concluídas as obras. Importante destacar que o valor a ser pago pelo terreno será calculado com base na situação do imóvel antes da área valorizar-se em função da realização das melhorias, pois o consórcio não poupa a propriedade de sanções previstas no plano diretor (art. 46, § $2^{\circ}$, do Estatuto da Cidade).

Aos problemas vinculados à aplicação somam-se limitações oriundas de fragilidades estruturais das máquinas municipais que, como verificado em Brasil (2015), abarcam, entre outros, cadastros imobiliários e fiscais não atualizados e integrados, limitada capacidade institucional e ausência de sistemas de planejamento. Essas condições comprometem a aplicação criteriosa dos instrumentos e podem até mesmo redundar em judicialização dos processos, com prejuízos nos tempos de espera de resultados. 
15 Essa situação não pode ser interpretada como imóvel não utilizado visto que os mesmos cumprem função social de servir como alojamento para turistas.

16 Pode-se considerar Praia Grande como um município em transição, visto que constitui a nova fronteira de expansão urbana regional.

17 Esses municípios tem no turismo a principal atividade econômica e apresentam uma quantidade de imóveis de segunda residência que supera a de ocupados de forma permanente.

180 Plano Diretor de Bertioga encontra-se em processo de revisão.

\section{Panorama da regulamentação e aplicação do PEUC nos municípios da RMBS}

A RMBS é composta por nove municípios: Santos, São Vicente, Cubatão, Guarujá, Praia Grande, Mongaguá, Itanhaém, Peruíbe e Bertioga. São seus principais eixos econômicos o porto de Santos, o maior da América Latina, e o polo industrial de Cubatão, constituído pela refinaria Presidente Bernardes, pela Usiminas, antiga Companhia Siderurgica Paulista, e por indústrias químicas ligadas ao ramo petrolífero e fertilizantes. Graças a esse conjunto de atividades, a região exibe alto grau de urbanização (99,83\%), segundo a Fundação SEADE (2019), com população residente de 1.814 .949 habitantes.

Embora os municípios da região sejam de médio e pequeno porte, as atividades portuárias e industriais tornam a região das mais dinâmicas do ponto de vista econômico. Além disso, com exceção de Cubatão, que não tem orla marítima, a RMBS apresenta atividade turística nos demais municípios, o que faz aumentar enormemente a população nos períodos de temporada. Esse turismo é do tipo balneário, caracterizado pela sazonalidade e pela segunda residência como modalidade de hospedagem, trazendo como consequência grande ociosidade do estoque de imóveis que permanecem desocupados a maior parte do ano, pois são utilizados apenas em férias e feriados ${ }^{15}$.

Santos, polo regional, e municípios limítrofes, São Vicente e Guarujá, por não dependerem exclusivamente do turismo como base econômica, desde os anos 1970 passaram por processo de conversão do estoque imobiliário de uso ocasional em permanente. Por isso não sentem com a mesma intensidade os efeitos negativos da sazolanlidade e da ociosidade da ocupação, como Praia Grande ${ }^{16}$, Mongaguá, Itanhaem, Peruibe e Bertioga ${ }^{17}$. Porém, em qualquer dos casos, o resultado dessa modalidade de uso do solo se reflete na alta valorização das orlas maritimas, onde predominam edifícios de apartamentos de veraneio, e a fragmentação da ocupação para o interior do território dos municípios, onde reside a maior parte da população e verifica-se alta incidência de precariedade habitacional, com avanço da ocupação de áreas de preservação permanente.

Todos os municípios da região possuem planos diretores, mas a adequação dos mesmos ao Estatuto da Cidade é bastante desigual. Os planos de Cubatão e Bertioga ${ }^{18}$, são anteriores ao Estatuto da Cidade. Com exceção do Plano de Bertioga, Lei n 315/1999, que não faz nenhuma menção, os demais citam o PEUC. O Quadro 1 apresenta a situação da regulamentação do PEUC na RMBS.

O Plano de Cubatão, Lei Complementar $n^{\circ}$ 2.512/1998, refere-se ao PEUC como instrumento para incentivar a ocupação de lotes vazios ou subutilizados, visando otimizar a infraestrutura instalada e os serviços urbanos existentes (art. $6^{\circ}$ ). A norma cita a utilização do PEUC, IPTU Progressivo no Tempo e a Desapropriação com Pagamento em Títulos da Dívida Pública, como ferramentas para alcançar a finalidade a que se propõem. mas os instrumentos não foram regulamentados, mesmo após a aprovação do Estatuto da Cidade, fator que impossibilita sua aplicação.

O Plano Diretor de Mongaguá, que sofreu revisão por meio da Lei n².167/2006, define em seus objetivos que o ordenamento do uso do solo deve evitar a retenção 
Quadro 1: Regulamentação do PEUC nos municípios da RMBS. Fonte: Prefeituras municipais (2019).
19 Este município criou a Comissão de Análise de Gerenciamento dos Instrumentos do Estatuto da Cidade, pelo Decreto ${ }^{\circ} 8.455$, de 20 de maio de 2019, que tem como incumbência, dentre outras, a gestão do PEUC. Embora os trabalhos de campo da Comissão, para identificação das situações que demandam PEUC, tenham se iniciado no mesmo ano, tiveram que ser interrompidos em virtude da Pandemia de COVID-19 e não foram retomados.

\begin{tabular}{l|c|c|c|l}
\hline Município & $\begin{array}{c}\text { Existência } \\
\text { de PD }\end{array}$ & $\begin{array}{c}\text { Menção do } \\
\text { PEUC no PD }\end{array}$ & $\begin{array}{c}\text { Regulamentação } \\
\text { do PEUC }\end{array}$ & Observação \\
\hline Bertioga & $\operatorname{Sim}$ & Não & Não & PD anterior ao EC \\
\hline Cubatão & $\operatorname{Sim}$ & $\operatorname{Sim}$ & Não & PD anterior ao EC \\
\hline Guarujá & $\operatorname{Sim}$ & $\operatorname{Sim}$ & $\operatorname{Sim}$ & Em lei específica \\
\hline Itanhaém & $\operatorname{Sim}$ & $\operatorname{Sim}$ & Não & \\
\hline Mongaguá & $\operatorname{Sim}$ & $\operatorname{Sim}$ & Não & \\
\hline Peruíbe & $\operatorname{Sim}$ & $\operatorname{Sim}$ & Não & \\
\hline Praia Grande & $\operatorname{Sim}$ & $\operatorname{Sim}$ & Não & \\
\hline Santos & $\operatorname{Sim}$ & $\operatorname{Sim}$ & Sim & Diretamente no PD \\
\hline São Vicente & $\operatorname{Sim}$ & $\operatorname{Sim}$ & Sim & Diretamente no PD \\
\hline
\end{tabular}

especulativa do imóvel urbano, que resulte na sua subutilização ou não utilização (art. 10, III e X), mas ao invés de incorporar o PEUC e instrumentos associados, para materializar esses objetivos, remete de forma genérica ao Estatuto da Cidade, não gerando condições efetivas para alcançá-los.

Os Planos Diretores dos municípios de Santos (Lei Complementar n 1.005/2018), São Vicente (Lei Complementar n 917/2018), Guarujá (Lei Complementar n 156/2013), Praia Grande (Lei Complementar n 727/2016), Itanhaém (Lei Complementar n 168/2015) e Peruíbe (Lei Complementar $n^{\circ}$ 100/2007) são os mais completos. Além de preverem o PEUC, Guarujá, Itanhaém e Peruíbe citam expressamente o combate à retenção especulativa entre seus objetivos. Os de Santos e São Vicente citam o cumprimento da FSP e o de Praia Grande a reserva de áreas para garantir programas habitacionais de interesse social.

Para atender esses objetivos, esses municípios avançaram na definição de áreas urbanas onde o instrumento será aplicado, definem os parâmetros para identificar os lotes, glebas não utilizados e subutilizados e as edificações sem utilização, assim como prazos para inicio da aplicação do IPTU Progressivo no Tempo.

Entretanto, com exceção de Santos ${ }^{19}$ e São Vicente, que estabelecem no próprio Plano Diretor como se dará a gradação da cobrança e de Guarujá que aprovou lei específica sobre a materia, os demais municípios não têm condições legais de trabalhar por não terem o instrumento regulamentado. Em Peruíbe o Executivo chegou a encaminhar projeto de lei à Câmara, mas esta rejeitou a matéria.

Com bases jurídica e institucional bem estruturadas, Santos foi o único município da região a avançar na aplicação do PEUC, mas limitou-se até agora a duas notificações. Uma referente a gleba vazia inserida em ZEIS, junto à favela Vila Pantanal, no bairro Saboó, na Zona Noroeste da área insular do município. O processo encontra-se no estágio de aplicação do IPTU Progressivo, pois o proprietário não deu entrada no projeto de parcelamento. Outra notificação refere-se a imóvel edificado não utilizado localizado no bairro do Valongo, na área central, cujo proprietário providenciou a reocupação atendendo as exigências da Prefeitura. 
$20 \mathrm{Na}$ área central encotram-se os bairros mais antigos, cuja formação remonta ao final do século XIX

21 Nesta área foi delimitada como ZEIS 3 um setor urbano, com objetivo não alcançado de promover a melhoria das condições de habitabilidade de cortiços, que tiveram aumento de $258 \%$, no período estudado.

Figura 1: Área Central de Santos: evolução dos lotes vazios, desocupados e em ruínas (1985 - 2014). Fonte: Prefeitura de Santos, Secretaria de Desenvolvimento Urbano (2016).
Desta forma, o volume de notificações é incipiente, apesar da grande quantidade de imóveis que demandam tal medida (Figura 1), como os existentes nos bairros da área central ${ }^{20}$, cujo fenômeno de esvaziamento foi estudado por Barros e Carriço (2019, p.12), revelando ampliação de aproximadamente $115 \%$ de imóveis desocupados.

A população dessa área, que era de 44.401 habitantes, em 1950, caiu para 4.307, em 2010 enquanto que, no mesmo período, houve aumento da população residente em áreas desprovidas de infraestrutura e com risco geológico, como nas encostas dos morros da cidade, como apontam os Censos Demográficos IBGE (BARROS; CARRIÇO, 2019, p. 4). Paradoxalmente, entre 1985 e 2014, a quantidade de imóveis desocupados sofreu aumento de $115 \%$, embora a de vazios tenha reduzido em $45 \%$, segundo levantamento da Prefeitura (BARROS; CARRIÇO, 2019, p. 4). Portanto, no caso do município polo, embora a ocupação de lotes vagos na área central tenha se ampliado, agravou-se a não utilização de imóveis, em uma das áreas com maior empregabilidade da região.

Os autores destacam que, embora desde 1992 a área central conte com ZEIS21, suas diretrizes nunca se materializaram, porque o PEUC não foi aplicado e nem

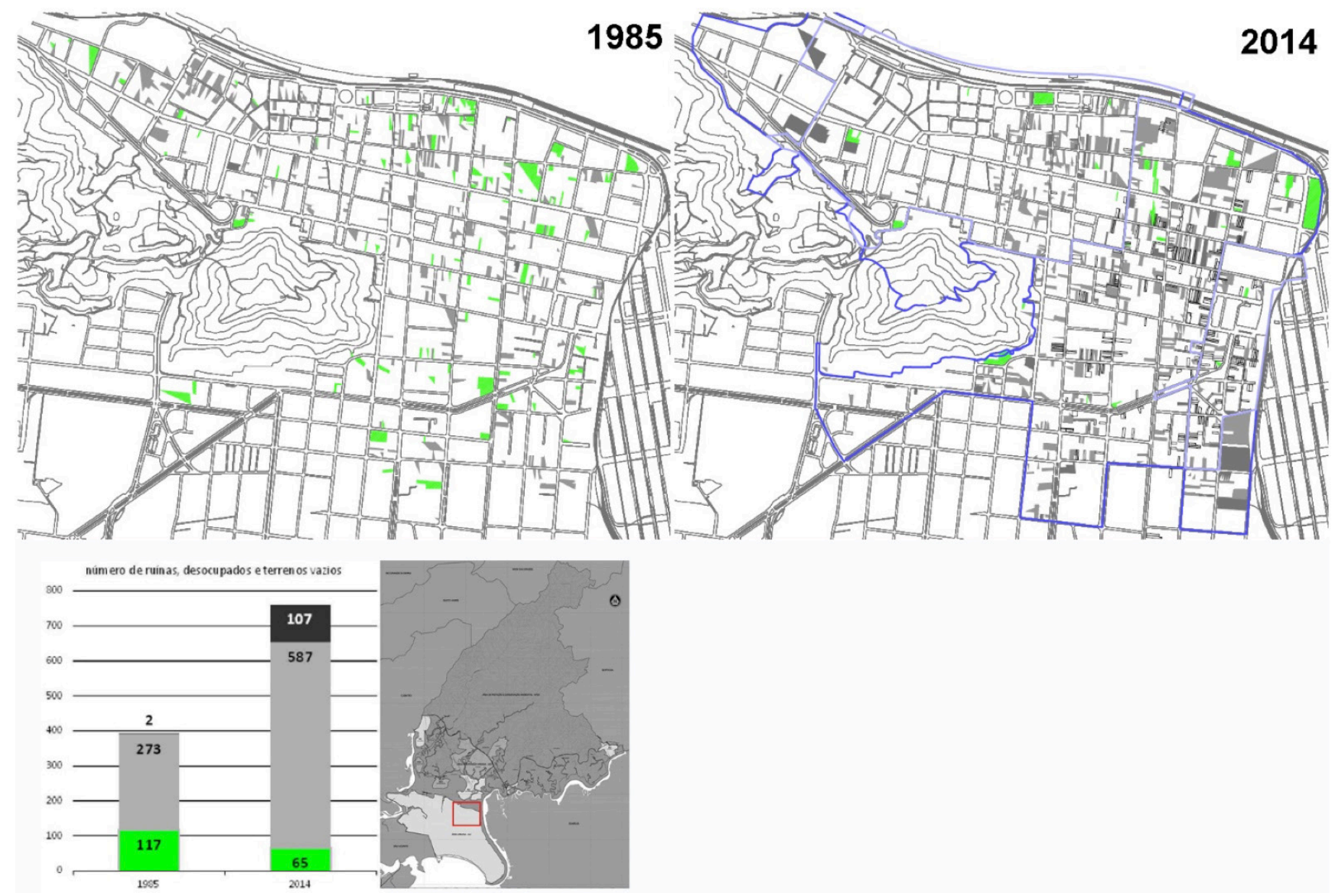


implementados outros instrumentos que fariam a área central mais atraente para investimentos em habitação. A utilização do estoque ocioso de imóveis da área central de Santos, como moradia para famílias de baixa e média rendas, em um contexto mais geral de repovoamento desta área, seria estratégico e muito mais sustentável, em face do crescimento periférico apontado neste trabalho.

\section{Considerações finais}

A urbanização no modo de produção capitalista é acompanhada pela valorização do solo, fator que exacerba os problemas das cidades de países que apresentam grande desigualdade social. Nelas a urbanização cria espaços ocupados por habitações carentes de infraestrutura, equipamentos e serviços, situação que, além de encarecer a ação do poder público no provimento de condições básicas de urbanização, produz grave passivo social e é responsável por degradação de recursos naturais e ambientais. Esse tipo de crescimento, chamado de "desordenado", ocorre a despeito da existência de vazios nos espaços urbanizados e é consequência dessa dinâmica de valorização, que tem como alicerce a especulação imobiliária.

Ao fixar a FSP como princípio a ser observado no trato da questão urbana e oferecer o PEUC e os instrumentos de sanção a ele articulados, como ferramentas para materializála, a CF de 1988 permite que o poder público municipal tenha capacidade de interferir na dinâmica de valorização imobiliária e controlar um dos problemas estruturais que mais afeta a sustentabilidade das cidades.

Nos 31 anos de vigência da CF, foram tímidos os avanços na aplicação do instrumento nos municípios brasileiros e por vezes houve distorção na sua efetivação, conforme demonstrado. Os dados referentes aos municípios da RMBS não são muito diferentes. Embora todos tenham plano diretor e alguns tenham regulamentado o PEUC, somente o município polo notificou um único proprietário, dando início ao processo de busca pelo cumprimento da FSP.

Entre os motivos para a baixa utilização do PEUC há que se considerar o tempo longo demandado na implementação dos instrumentos associados, agravado pela impossibilidade de utilização da Desapropriação com Pagamento em Títulos da Dívida Pública, fatores que desestimulam gestores públicos. A isso juntam-se outros entraves, tanto de ordem política, relacionados com contradições que vão desde o caráter ao mesmo tempo social e liberal da CF, até pressões do setor imobilário sobre governos municipais, sempre que a possibilidade de utilizar medidas coercitivas é debatida ou colocada em prática. A isso juntam-se limitações técnicas, financeiras e institucionais da maioria dos municípios, inclusive para lidar com situações de juficialização que a aplicação do instrumento possa ensejar.

Não restam dúvidas de que a aplicação do PEUC e instrumentos sucessivos é fundamental, na perspectiva da construção de cidades cidades menos desiguais do ponto de vista socioespacial. No entanto, os procedimentos existentes para conter processos especulativos sobre o solo urbano se debatem com fragilidades que exigem reflexão e uma luta contínua, no sentido de mudanças para tornar o Estado mais apto a induzir crescimento urbano sustentável. 


\section{Referências bibliográficas}

BARROS, M. F. CARRIÇO, J. M. Esvaziamento e transformação morfológica da área central de Santos-SP: gênese e perspectivas. Curitiba: Urbe - Revista Brasileira de Gestão Urbana, 2019. Disponível em: <http://www.scielo.br/pdf/urbe/v11/2175-3369-urbe-11-e20180100. pdf $>$. Acesso em: 14 ago. 2019.

BERNARDES, J. T. Da definição social da propriedade imóvel-estudos do princípio constitucional e sua regulamentação pelo Código Civil brasileiro. [on line] Juscom.br, 2003. Disponível em: <https://jus.com.br/artigos/4573/da-funcao-social-da-propriedade-imovel>. Acesso em 18 jul. 2019.

BRASIL. Lei Federal no 10.257/2001. Estatuto da Cidade. Regulamenta os arts. 182 e 183 da Constituição Federal, estabelece diretrizes gerais da política urbana. Brasília: D.O.U, 11 jul. 2001.

Constituição da Republica Federativa do Brasil. Disponível em: <www.planalto.gov. br/ccivil_03/constituicao/constituicao.htm>. Acesso em: 14 set. 2014.

BRASIL (Ministério da Justiça); INSTITUTO DE PESQUISA ECONÔMICA APLICADA. PEUC e IPTU Progressivo no Tempo - regulamentação e aplicação. Brasília: Ministério da Justiça, IPEA, 2015. Disponível em: <http://pensando.mj.gov.br/wp-content/uploads/2015/11/ PoD_56_web1.pdf. Acesso em: 22 abr. 2018.

BRASIL (Senado Federal). Resolução n 43, de 21 dezembro de 2001. Disponível em: <https:// legis.senado.leg.br/norma/582604/publicacao/15732530>. Acesso em: 26 jun. 2019.

CASTILHO, J. R. F. Instrumentos de combate à especulação imobiliária. Monografia. Curso de Pós-graduação em Geografia, FCT/UNESP. Presidente Prudente: UNESP, 1993. Disponível em: <http://revista.fct.unesp.br/index.php/formacao/article/view/1066/1072>. Acesso em: 14 ago. 2019.

CYMBALISTA, R.; FREIRE, P. Planos Diretores - processos e aprendizados. São Paulo: Instituto Polis, 2009. Disponível em: <http://www.polis.org.br/uploads/1010/1010.pdf>. Acesso em 03: ago. 2019.

FROTA, H. B. Cidade em debate - Uso do Solo, Parcelamento, Edificação e Utilização Compulsórios. [on line] Curitiba: IBDU, 2014. Disponível em: <http://www.urbanismo.mppr.mp.br/ arquivos/File/CidadeemDebate_Curitiba_Henrique_27_11_14.pdf>. Acesso em 27/06/2019.

FUNDAÇÃo SISTEMA ESTADUAL DE ANÁLISE DE DADOS ESTATÍsTICOS. Perfil dos Município Paulistas. Região Metropolitana da Baixada Santista [on line]. São Paulo: SEADE, 2019. Disponível em: <http://www.perfil.seade.gov.br/\#>. Acesso em: 14 ago. 2019.

INSTITUTO BRASILEIRO DE DIREITO URBANISTICO. Nota Técnica. Coletivo A Cidade Que Queremos. 26 jun. 2019. Disponível em: <http://www.ibdu.org.br/notas/nota-tecnica-sobre-a-pec80-2019>. Acesso em: 24 ago. 2019.

MACHADO, S. B. dos S. Propriedade privada e função social: o regime jurídico da propriedade urbana no Brasil. Dissertação (Mestrado) Programa de Pós-Graduação em Direito da Faculdade de Direito do Sul de Minas. Pouso Alegre, 2014. Disponível em: <https://www.fdsm. edu.br/mestrado/arquivos/dissertacoes/2014/04.pdf>. Acesso em: 26 jun. 2019.

MAGALHÃES, A. F.; RIBEIRO, T. F. Só quero saber do que pode dar certo, não tenho tempo a perder: o problema dos vazios urbanos e da não aplicação do parcelamento/edificação/ utilização compulsórios. [on line] Rio de Janeiro, 2016. Disponível em: <https://www.academia.edu/attachments/53842018/download_file?st=MTU2NzQzMTQ5NCwxOTguNDku MTMzLjI0OQ\%3D\%3D\&s=swp-splash-header>. Acesso em: 29 jun. 2019.

PLANJETAR. 68,3\% dos municípios possuem menos de 20 mil habitantes. [on line] Disponível em: <http://planjetar.com.br/683-dos-municipios-brasileiros-possuem-menos-de-20-mil-habitantes/\#.XT8C3fJKjIV>. Acesso em: 27 jul. 2019. 
RODRIGUES, M. R. O princípio da função social e a constitucionalização do direito civil: instrumentos jus urbanísticos previstos no Estatuto da Cidade. [on line] São Paulo: Empório do Direito, 11 jul. 2018. Disponível em: https://emporiododireito.com.br/leitura/o-principio-da-funcao-social-e-a-constitucionalizacao-do-direito-civil-instrumentos-jus-urbanisticos-previstos-no-estatuto-da-cidade. Acesso em: 13 ago. 2019.

SALEME, E. R. Comentários ao Estatuto da Cidade - com destaque às leis 11.977/2009, 12.587/2012, 13.089/2015 e 13.465/2017. Belo Horizonte: Arraes, 2018.

SÃO PAULO (Legislativo). Índice Paulista de Responsabilidade Social 2014. Região Metropolitana da Baixada Santista. São Paulo: Fundação Seade, 2016. Disponível em: <http://www.iprs. seade.gov.br/iprs2016/view/pdf/iprs/reg680.pdf>. Acesso em: 09 ago. 2019.

SANTOS, R.S.F. dos. Do urbanismo sanitarista ao planejamento urbano estratégico em Santos, SP: o (re)significado das funções sociais da cidade e da propeiedade. Santos, SP. Dissertação de Mestrado. Universidade Católica de Santos. Programa de Pós Graduação Stricto Sensu em Direito Ambiental, 2018.

SAULE JR. N.; UZZO, K. A trajetória da reforma urbana no Brasil. [on line] 2009. Disponível em: http://base.d-p-h.info/pt/fiches/dph/fiche-dph-8583.html. Acesso em 14 ago. 2019.

SANCHES, J. R.; ARAUJO JR., M. E.; CENCI, E. M. Crise do Estado e o IPTU Progressivo no Tempo como instrumento de intervenção no espaço urbano. Revista do Direito Público. Londrina. v.13, n.1, p.259-290, abril 2018. Disponível em: <http://www.uel.br/revistas/uel/index.php/ direitopub/article/download/30145/23481>. Acesso em 13 ago. 2019. 